\title{
A rare form of heterotopic pregnancy: cervical pregnancy and intrauterine pregnancy
}

Mehmet Kulhan, Nur Gozde Kulhan, Umit Nayki, Cenk Nayki, Nahit Ata

Department of Gynecology and Obstetrics, School of Medicine, Erzincan University, Erzincan, Turkey

Submitted: 26 February 2017

Accepted: 25 July 2017

Arch Med Sci Civil Dis 2017; 2: e110-e112

DOI: https://doi.org/10.5114/amscd.2017.70520

Copyright $\odot 2017$ Termedia \& Banach

Heterotopic pregnancy refers to the presence of simultaneous pregnancies at two different implantation sites. Most often these sites are a combination of intrauterine and ectopic pregnancies, rather than two ectopic pregnancies [1]. Heterotopic pregnancy used to be rare, estimated to occur in 1 in 30,000 pregnancies [1]. With the advent of assisted reproduction techniques (ART), the overall incidence of heterotopic pregnancy has risen to approximately 1 in 3900 pregnancies [2]. Combination of cervical pregnancy and intrauterine pregnancy is a rare form of heterotopic pregnancies. A spontaneous rare form of heterotopic pregnancy that combined cervical and intrauterine pregnancy is presented.

The patient (age 33, gravida: 5, parity: 3, abortus: 1 ) applied to our clinic for routine antenatal examination at the eighth week of the pregnancy for the first time. The patient had in her history a c-section operation seven months ago. After physical examination and ultrasonographic evaluation, heterotopic pregnancy was determined. The patient did not have defense and rebound sensitivity during the abdominal examination and the collum movements were determined to be severely painful during the gynecological examination. In the ultrasonographic evaluation, there was a 7-week fetus with cardiac activity in the cervical canal and the formation of a hyperechogenic echo that was thought to be a gestational sac with yolk sac in the uterine cavity. However, widespread free fluid collection was not observed inside the paraovarian region, Douglas cavity or abdomen (Figure $1 \mathrm{~A}$ ). The $\beta$-human chorionic gonadotropin ( $\beta$-hCG) level was 74,627 IU/l, and the progesterone level was $7.17 \mathrm{ng} / \mathrm{ml}$. We treated the hemodynamically stable woman with cervical pregnancy medically using $75 \mathrm{mg}$ single dose methotrexate (MTX) therapy without intraamniotic or intrafetal injection of local potassium chloride $(\mathrm{KCL})$. The $\beta$-hCG level was $36935 \mathrm{IU} / \mathrm{l}$ and the progesterone level was $4.74 \mathrm{ng} / \mathrm{ml} 4$ days after methotrexate. In the ultrasonographic evaluation, cardiac activity was not observed, but there was formation of a hyperechogenic echo in both the cervical canal and the uterine cavity (Figure $1 \mathrm{~B}$ ). Therefore, we used $200 \mu \mathrm{g}$ of prostaglandin E1 (PGE1, misoprostol) intravaginally to provide abortion. One day after this treatment the patient aborted. There were no complications after the treatment. There were no problems in the follow-ups after discharge. The patient was called for regular routine check-ups and her hemoglobin value was $13.2 \mathrm{~g} / \mathrm{dl}$; however, the ultrasonographic and gynecologic examination were evaluated as normal. She was informed in detail regarding the possible obstetric and gynecologic situations that might arise in her next pregnancy.

\author{
Corresponding author: \\ Mehmet Kulhan \\ Department of Gynecology \\ and Obstetrics \\ School of Medicine \\ Erzincan University \\ Basbaglar mah \\ 24030 Erzincan, Turkey \\ Phone: +90 5054918090 \\ E-mail: Mehmet kulhan@ \\ yahoo.com
}



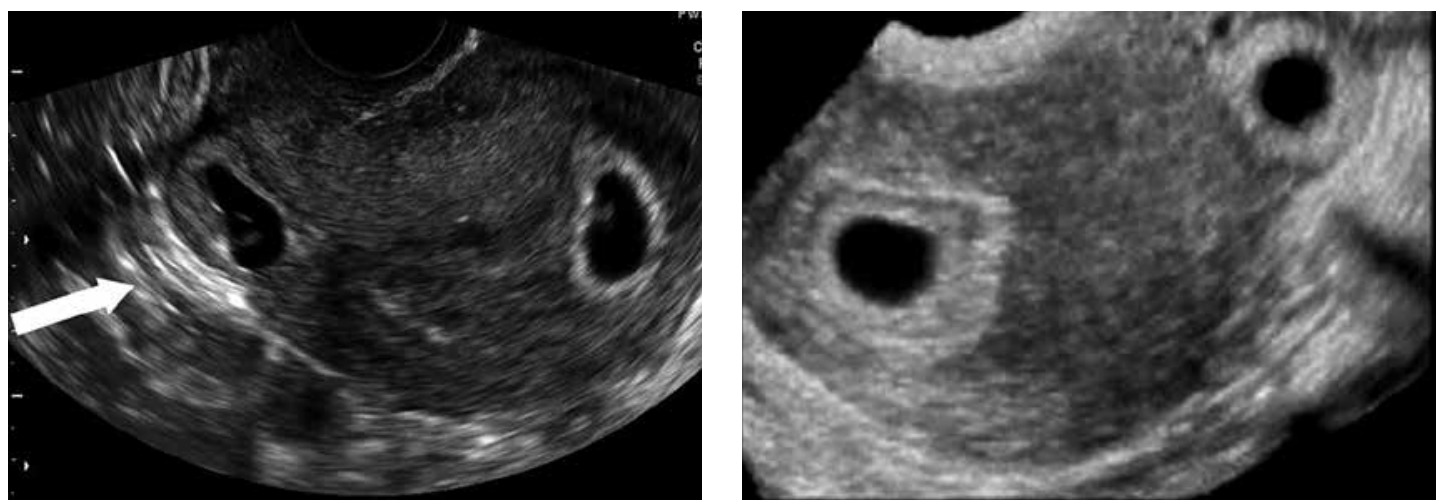

Figure 1. A - Before MTX treatment, B - after MTX treatment

Cervical pregnancy is a rare form of ectopic pregnancy in which the pregnancy implants in the lining of the endocervical canal. It accounts for less than $1 \%$ of ectopic pregnancies [3]. The cause is unknown; local pathology related to previous cervical or uterine surgery may play a role given the apparent association with a prior history of curettage or cesarean delivery [4]. Another theory is rapid transport of the fertilized ovum into the endocervical canal before it is capable of nidation or because of an unreceptive endometrium.

The most common symptom of cervical pregnancy is vaginal bleeding, which is often profuse and painless [4]. Lower abdominal pain or cramps occur in fewer than one-third of patients; pain without bleeding is rare. It is important to consider the possibility of cervical pregnancy in such patients since early diagnosis is critical for avoidance of complications and successful treatment.

The term cervical abortion has been used to describe an aborting intrauterine pregnancy that is trapped in the endocervical canal because of resistance from the external cervical os. An intrauterine pregnancy in the process of aborting can mimic a cervical pregnancy if the products of conception have not passed through the external cervical os. This diagnosis is likely if ultrasound reveals some products of conception/blood clot in the uterine cavity, the uterine cavity is enlarged compared to the cervix, the internal cervical os is open, or the gestational sac is flattened and has no or a minimal echogenic rim and contains no or a dead embryo [5]. In addition, a cervical abortion should not show any signs of trophoblastic invasion of the cervical stroma or cardiac activity; the presence of intracervical peritrophoblastic blood flow by color/pulsed Doppler ultrasound or cardiac activity suggests a true cervical pregnancy. Cervical pregnancy rather than incomplete abortion is also suggested by a negative sliding sac sign: no movement of the intracervical sac when the vaginal transducer is used to apply gentle pressure to the cervix. The differential diagnosis also includes cesarean or hysterotomy scar pregnancy, which should be considered if the gestational sac is in the anterior lower uterine segment and the uterine cavity and endocervical canal are empty [6].

Treatment of the ectopic pregnancy should be tailored to the site of implantation and should use the least invasive therapy in order to preserve the concomitant intrauterine pregnancy. Systemic medical therapy (e.g. methotrexate) is contraindicated in the presence of a viable intrauterine gestation [7]. Salpingectomy is the standard surgical approach of a coexistent tubal pregnancy, and should be the first line of treatment in patients with hemodynamic instability or other signs of tubal rupture. A laparoscopic approach is desirable if the patient is hemodynamically stable.

In expert hands, if the pregnancy has not ruptured, then local injection into the sac under sonographic guidance is an effective treatment. Substances for injection should have high therapeutic effectiveness with low toxicity to the concurrent intrauterine pregnancy, and produce no lasting damage to the fallopian tube [8]. Two options are potassium chloride (KCL) and hyperosmolar glucose [8]. A report of a cervical pregnancy treated with $\mathrm{KCL}$ injection was complicated by delayed bleeding, which was controlled by placement of cervical stay sutures [8]. The co-existing intrauterine pregnancy progressed to term. A heterotopic cesarean scar pregnancy combined with an intrauterine pregnancy was successfully treated by selective embryo reduction by aspiration [9].

Informed consent was obtained from the participant.

\section{Conflict of interest}

The authors declare no conflict of interest.

\section{References}

1. Reece EA, Petrie RH, Sirmans MF, et al. Combined intrauterine and extrauterine gestations: a review. Am J Obstet Gynecol 1983; 146: 323-30. 
2. Gruber I, Lahodny J, Illmensee K, Lösch A. Heterotopic pregnancy: report of three cases. Wien Klin Wochenschr 2002; 114: 229-32.

3. Bouyer J, Coste J, Fernandez H, Pouly JL, Job-Spira N. Sites of ectopic pregnancy: a 10 year population-based study of 1800 cases. Hum Reprod 2002; 17: 3224-30.

4. Vela G, Tulandi T. Cervical pregnancy: the importance of early diagnosis and treatment. J Minim Invasive Gynecol 2007; 14: 481-4.

5. Hofmann HM, Urdl W, Höfler H, et al. Cervical pregnancy: case reports and current concepts in diagnosis and treatment. Arch Gynecol Obstet 1987; 241: 63-9.

6. Maymon R, Halperin R, Mendlovic S, et al. Ectopic pregnancies in a Caesarean scar: review of the medical approach to an iatrogenic complication. Hum Reprod Update 2004; 10: 515-23.

7. Wyroba J, Krzysiek J, Rajtar-Ciosek A, et al. High live birth rate after conservative treatment of ectopic pregnancy with methotrexate. Ginekol Pol 2014; 85: 105-10.

8. Goldberg JM, Bedaiwy MA. Transvaginal local injection of hyperosmolar glucose for the treatment of heterotopic pregnancies. Obstet Gynecol 2006; 107: 509-10.

9. Hsieh BC, Hwang JL, Pan HS, et al. Heterotopic Caesarean scar pregnancy combined with intrauterine pregnancy successfully treated with embryo aspiration for selective embryo reduction: case report. Hum Reprod 2004; 19: 285-7. 